\title{
Patterns and mechanisms of conspecific and heterospecific interactions in a dry perennial grassland
}

\author{
Emily C. Farrer* and Deborah E. Goldberg \\ Department of Ecology and Evolutionary Biology, University of Michigan, Ann Arbor, MI 48109, USA
}

\begin{abstract}
Summary
1. Models of local stable coexistence require negative feedbacks, i.e. intraspecific interactions must be more negative than interspecific interactions. However, most competition experiments, often done in the glasshouse, have found evidence for competitive hierarchies. Measurement of interactions under realistic field conditions is necessary to assess their contribution to community dynamics, and explicit measurement of intermediaries thought to be important in interactions may allow studies to account for any variation in experimental results.
\end{abstract}

2. In this study, we compare conspecific and heterospecific interactions in a field experiment in a dry sand prairie in Michigan. We study the four dominant species at two different stages, germination and adult growth. Using seed addition and adult transplant experiments, we ask whether plants perform best in natural field monocultures of conspecifics, heterospecifics or no neighbour plots. We also measure abiotic environmental characteristics associated with each neighbourhood type and test whether performance can be explained by environmental effects. We hypothesize that plants will create competitive hierarchies because our experimental design is similar to classic competition experiments.

3. Neighbour species created consistent hierarchies in their effects on germination of all four target species, which is likely due to light limitation. However, interestingly, adult plant biomass for two of the three species (one species did not survive) was lower in conspecific monocultures compared to heterospecific or no neighbour plots, thus producing negative feedbacks. For two species, the effects of neighbours on adult growth are likely due to reduction of light and soil nitrate; for the third, however, resources could not explain the pattern that conspecific interactions were more negative than heterospecific.

4. Synthesis. These results suggest that patterns in the relative strength of conspecific and heterospecific competition depend on life-history stage. Moreover, resource uptake could explain some, but not all, of the interactions among species, suggesting that other factors such as microbial communities or other forms of niche partitioning may play a role and that field experiments are necessary to gauge their relative importance.

Key-words: coexistence, competition, competitive hierarchy, facilitation, germination, intraspecific vs. interspecific interactions, plant-soil feedbacks

\section{Introduction}

Models of local stable coexistence require negative feedbacks, in that intraspecific interactions must be more negative than

*Correspondence author. Department of Environmental Science, Policy \& Management, University of California Berkeley, 137 Mulford Hall \#3114, Berkeley, CA 94720, USA. E-mail: ecfarrer@ berkeley.edu interspecific interactions at the population-level (Chesson 2000; Chase \& Leibold 2003; Silvertown 2004). Despite the importance of this condition for coexistence, remarkably few empirical studies in plants explicitly test whether it holds for coexisting species (Silvertown 2004). Although a huge literature documents the importance of competition and facilitation for individual plant performance, and includes field and glasshouse competition experiments (Keddy 2001) and studies on facilitation (Callaway \& Walker 1997), succession (Tilman 
1990) and plant-soil feedbacks (Bever 2003), many of these studies cannot address coexistence because they do not compare intra- and interspecific effects. For example, facilitation research tends to focus only on interspecific effects, such as the effects of shrubs on understorey plants and vice versa. The succession literature often focuses on unidirectional effects of early successional species on late-successional ones. Most field competition experiments examine the effect of the entire community of competitors on individual species but do not measure pairwise interactions. Thus, it is much less clear how individual interactions affect community dynamics and, specifically, coexistence (Goldberg, Turkington \& Olsvig-Whittaker 1995).

The relatively few field and glasshouse competition experiments that explicitly compare conspecific and heterospecific interactions tend to find no general pattern in their relative strength; instead consistent competitive hierarchies are common (Goldberg \& Barton 1992; Gurevitch et al. 1992; Shipley \& Keddy 1994; Goldberg 1996; but see Fargione, Brown \& Tilman 2003). On the other hand, plant-soil feedback experiments, in which species are grown, without live plant competitors, in soil cultivated by conspecifics or heterospecifics, often find evidence for negative feedbacks, that is, effects from conspecific soil are more negative than heterospecific (Kulmatiski et al. 2008). These contradictory results suggest that the presence (or absence) of live neighbour plants critically influences the outcome of plant interactions. Recent feedback studies have confirmed that adding direct resource competition with live plants to microbial feedbacks can change the net magnitude and direction of plant effects (Casper \& Castelli 2007; Kulmatiski et al. 2008). This suggests that live plant competition should be included when testing interactions important for population dynamics and coexistence.

Many pairwise competition experiments and most feedback studies are done under highly controlled, often glasshouse, conditions and field tests of whether intraspecific interactions are more negative than interspecific interactions are lacking (Silvertown 2004; Kulmatiski et al. 2008). It is essential to determine whether this condition for coexistence is measurable in the field even in the presence of spatial and temporal variability, herbivory, and other ecological processes. Thus, experiments performed under realistic field conditions, including resource levels, substrate, plant densities and plant life-history stages, are necessary to capture the interactions that influence population dynamics.

Explicit measurement of the intermediaries through which the interactions are thought to occur may allow studies to account for variation in the mechanisms of interactions and hence their outcome. Competition experiments typically assume that plants interact primarily through resource uptake. However, the few competition experiments that have measured intermediaries have found that resource uptake could not account for all of the pairwise interactions and thus could not explain the mechanisms of coexistence of all species (Reynolds et al. 1997; Fargione, Brown \& Tilman 2003; Dybzinski \& Tilman 2007). This may indicate that components of the soil microbial community or other niche processes drive coexistence. In order to understand the net pairwise interactions that are important to population dynamics, field competition experiments should be combined with measurement of a range of potential intermediaries.

In this study, we compare the strength of conspecific and heterospecific interactions among the four dominant species in a dry sand prairie system at two life-history stages: seed germination and adult plant performance. Using seed addition and transplant experiments in the field, we measure performance with conspecific, heterospecific and no neighbours to understand pairwise plant-plant interactions. These interactions occur through species' effects on and responses to intermediaries in the environment. We thus measure abiotic environmental characteristics associated with each of these neighbourhoods in natural field monocultures to suggest whether species differentially affect the environment. To address the responses of species to the environment, we combine these two data sets and relate transplant performance to the environmental characteristics in the different neighbourhood types using crossspecies correlations. This could indicate which aspects of the environment are associated with variation in plant performance and thus may act as intermediaries in the species interactions. Because our experiment contains live neighbours, we hypothesize that plants in our system will generate competitive hierarchies, consistent with most results from the competition literature. Alternatively, results from a previous model-fitting study in this system suggest that conspecific interactions are more negative than heterospecific so that there are no consistent hierarchies (Farrer, Goldberg \& King 2010). Due to the dry, nutrient-poor conditions in the sand prairie, we hypothesize that abiotic environmental characteristics such as nutrients and moisture will be limiting and will be important intermediaries in plant interactions.

\section{Materials and methods}

\section{STUDY SITE AND SPECIES}

Field work was carried out in the native dry sand prairie of the northern lower peninsula of Michigan near the city of Indian River (latitude $45^{\circ} 23^{\prime} 26^{\prime \prime} \mathrm{N}$, longitude $84^{\circ} 35^{\prime} 41^{\prime \prime} \mathrm{W}$ ). Dry sand prairie occurs on glacial outwash plains and is characterized by excessively welldrained, sandy, nutrient-poor soil (Albert 1995). Because of the flat topography and homogenous substrate of outwash sands, we assume that heterogeneity in soil characteristics is due primarily to plant effects. A long-term garden experiment is underway to test this assumption.

The study included the four dominant herbaceous species in the system, which together make up over $90 \%$ of the stems (E. C. Farrer, unpublished data): Carex pensylvanica, Danthonia spicata, Schizachyrium scoparium, and Hieracium piloselloides; nomenclature follows Voss $(1972,1996)$. The first three are dominant graminoids native to grasslands and open canopy habitats throughout North America and are characteristic of dry sand prairie (Kashian, Barnes \& Walker 2003; Kost et al. 2007). Hieracium piloselloides is an exotic from Europe; however it tends not to be invasive and is the rarest of the four species. We also include Cladina spp. (reindeer lichen) as a neighbour type in our study; these are important components in this system, occurring at about $30 \%$ cover. 
The seed addition experiment, transplant experiment and environmental measurements were all performed in natural monoculture plots in the field. Natural monoculture plots were defined as areas of at least $9 \times 9 \mathrm{~cm}$ dominated by one of the six neighbour types (bare soil, lichen, Carex, Danthonia, Hieracium, and Schizachyrium). This is the size of a typical natural patch of each of the species (E. C. Farrer, unpublished data) so although the field monocultures were constrained to be small, they are representative of realistic field heterogeneity. Plants in this system are small in stature (height range 2-25 cm for vegetative growth) and interact at these small scales (Farrer, Goldberg \& King 2010). Although some root ingrowth from other plants surrounding a $9 \times 9 \mathrm{~cm}$ patch is likely, the majority of active roots within a patch probably belonged to the monoculture species, because root biomass in bare and lichen patches was only $50 \%$ that of the patches with plant species and most of these roots appeared dead. The age of the natural monocultures and bare patches is unknown; the plant species remained dominant in their natural monocultures for the 2 years of the study. Bare patches contained small amounts of old above-ground litter and old roots, indicating that they had been inhabited by plants previously, but they remained bare throughout the study. The natural monoculture plots were arranged in $2 \times 5 \mathrm{~m}$ blocks, which was sufficient to contain enough natural monoculture plots for one replicate of each treatment in a given experiment. The blocks were arranged in separate transects for each experiment as described below.

\section{PERFORMANCE EXPERIMENTS}

\section{Seed addition experiment}

For the seed addition experiment, one target species' seeds were added to each natural monoculture plot, so that one replicate block of this experiment consisted of 24 natural monoculture plots (four target species $\times$ six neighbour types). Ten replicate $2 \times 5 \mathrm{~m}$ blocks were laid out in two transects measuring $20 \times 5 \mathrm{~m}$ in the study site (blocks were not continuous).

In late May and in late August 2007, seeds of the selected target species were added to the centre of the natural monoculture plots. Seeds added in May 2007 were collected from the study site in 2006. Seeds added in August 2007 were collected from the study site in 2007 (for Carex, Danthonia, and Hieracium which had flowered in June) or 2006 (for Schizachyrium which flowers in September). In all cases, seeds were kept refrigerated at $4{ }^{\circ} \mathrm{C}$ from collection until planting.

In May, seeds added for Danthonia, Hieracium, and Schizachyrium were based on germination rates in the laboratory $(20 \%, 60 \%$, and $24 \%$, respectively) and were aimed at yielding approximately six seedlings per plot. No Carex seeds geminated in the laboratory, so the number of seeds added was based on seed availability; Carex produces few seeds and many are non-viable due to perigynium smut infection (A. A. Reznicek, personal communication). Seeds were added again to the same plots in August, because no seedlings were yet observed in the plots. The total number of seeds added per plot (May + August) was 30 for Carex, 60 for Danthonia, 30 for Hieracium, and 60 for Schizachyrium.

The number of seedlings in each of the plots was censused in early June 2008, and germination rate was calculated as number of seedlings in June/total number of seeds added. Number of seedlings was censused again in late August 2008, and establishment rate was calculated as number of seedlings in August/total number of seeds added. Establishment rates were too low to be analysed statistically, however they are shown with the means for germination rate in Appendix S2 in Supporting Information.

\section{Adult transplant experiment}

Each natural monoculture plot received one transplant of a given target species, so one replicate block of this experiment consisted of 24 natural monoculture plots (four target species $\times$ six neighbour types). Ten replicate blocks were arranged continuously in a $20 \times 5 \mathrm{~m}$ transect in the study site, separate from the seed addition transects.

Each transplant consisted of a clone of three connected ramets, although for Hieracium ramets were not necessarily still connected because the rhizomes decompose quickly and break easily. Transplants were planted as a clone to allow for integration among ramets, which is important for clonal spread (Fischer \& van Kleunen 2002). Transplants were dug up from the study site within $0.25 \mathrm{~km}$ of the blocks, their roots washed to remove soil, and senescent tissue was removed. Rhizomes differed slightly in initial length, which was unavoidable to obtain a sufficient sample of three connected ramets (range 1-3 cm). Transplants were kept in water for a maximum of 2 days until planting.

Transplants were planted in the neighbourhoods from 25-28 May 2007. Those that died within the first 3 weeks were replaced. Transplants were watered approximately twice a week throughout June and July 2007 to aid establishment.

Plots with surviving transplants were harvested after two growing seasons in mid-August 2008. All neighbour species' stems in the $9 \times 9 \mathrm{~cm}$ plots were clipped for above-ground biomass, and litter mass was collected. The $9 \times 9 \mathrm{~cm}$ block of soil was then harvested to a depth of $20 \mathrm{~cm}$ and was frozen until roots and rhizomes of the target plant could be extracted and sorted. Noticeably dead parts of target rhizomes (those that were soft and decomposing) were not included in rhizome biomass. All samples were dried at $55^{\circ} \mathrm{C}$ and weighed.

\section{Statistical analyses}

From the seed addition and transplant experiments, four different measures were used to describe the performance of the target species in the six different neighbourhoods: germination rate, adult survival, biomass of surviving adult transplants (shoot + root + rhizome mass), and total adult performance (biomass of the surviving transplants and zero biomass for transplants that did not survive). Total performance thus combines both survival and growth of transplants, which is important for scaling from individual demography to population dynamics. Schizachyrium was not included as a target species in the adult analyses because its survival was so low (only 8 out of the original 60 transplants survived through the second summer).

For germination, adult biomass and adult total performance, relative performance was calculated by a log response ratio comparing performance in a given neighbour type (Carex, Danthonia, Hieracium, Schizachyrium, lichen) to their mean performance in bare plots: $\operatorname{lrr}=\ln$ (performance ${ }_{\mathrm{C}, \mathrm{D}, \mathrm{H}, \mathrm{S}, \mathrm{orL}} /$ mean performance bare ). This standardizes the species responses to their performance with no neighbours so responses can be compared among target species. The effect of target species, neighbour species and their interaction on log response ratios was analysed using linear mixed models. We tested two different models: first, neighbour type was classified by species with five different levels (lichen, Carex, Danthonia, Hieracium, Schizachyrium); second, neighbour type was classified with two levels, conspecific and heterospecific (see Appendix S1).

For adult survival, because data are binary, generalized linear mixed models were used to test the effect of target species, neighbour species, and their interaction. We tested the same two types of models as described above (neighbour type as five different levels and as 
conspecific/heterospecific) (Appendix S1). For figures, a log response ratio was calculated for survival to facilitate comparison with other performance measures (see Appendix S1).

\section{ASSOCIATIONS BETWEEN NEIGHBOUR SPECIES AND ENVIRONMENTAL CHARACTERISTICS}

Environmental characteristics thought to be potential intermediaries in plant interactions were measured in June and August 2007 and 2008 in a separate set of natural monoculture plots. Each replicate block contained five natural monocultures of each of the five species and five bare plots; four of these monocultures were used for destructive soil nutrient and live/litter biomass sampling and one was used for non-destructive repeated measurements of light and temperature ( 5 monocultures $\times 6$ neighbour types $=30$ monocultures per block). Ten replicate $2 \times 5 \mathrm{~m}$ blocks were contained in the same two $20 \times 5 \mathrm{~m}$ transects as the seed addition experiment; environmental blocks alternated with seed addition blocks to cover a large area of the grassland for sampling.

Available $\mathrm{NH}_{4}{ }^{+}$and $\mathrm{NO}_{3}{ }^{-}, \mathrm{N}$ mineralization and nitrification were measured using 1 month in situ buried bag incubations (Appendix S1). Gravimetric soil moisture and SOM (soil organic matter) were also measured from these soil cores $(2.54 \mathrm{~cm}$ diameter $\times 10 \mathrm{~cm}$ depth). Above-ground shoot and litter biomass in the area over the cores was clipped, sorted and dried at $55^{\circ} \mathrm{C}$ for the June 2007-2008 and August 2007 sampling periods (but not for the August 2008 period due to time constraints). Root and rhizome biomass was sorted from the August 2007 initial soil cores and dried at $55^{\circ} \mathrm{C}$, and total $\mathrm{C}$ and $\mathrm{N}$ of roots were measured by dry combustion (Appendix S1).

At each sampling period, the non-destructive measurements, light at the soil surface and soil temperature, were also taken in the remaining 60 monoculture plots (Appendix S1).

\section{Statistical analyses}

The relationship between neighbour species and environmental characteristics $\left(\mathrm{NH}_{4}{ }^{+}, \mathrm{NO}_{3}{ }^{-}, \mathrm{N}\right.$ mineralization, nitrification, moisture, SOM, temperature, light) was analysed using redundancy analysis (RDA) in Canoco 4.0 (ter Braak 1987; ter Braak \& Smilauer 1998). Neighbour species identity and neighbour characteristics (shoot and litter biomass) were treated as explanatory variables and environmental characteristics were treated as dependent variables. Season and block were used as covariables in the analysis (Appendix S1). A second RDA was also performed but using only the data from August 2007, because root biomass and C:N was sampled in this time period (Appendix S1).

\section{RELATING NET INTERACTIONS TO NEIGHBOUR AND ENVIRONMENTAL CHARACTERISTICS}

To link target performance to characteristics of the neighbours and their environments, we explored correlations between performance (germination and adult total performance) and (i) neighbour and litter mass from the transplant experiment and (ii) abiotic measurements from the environmental natural monocultures. For these cross-species analyses, we used means for each target-neighbour type combination as a single data point, because environmental characteristics were not measured in the same plots as plant performance and neighbour characteristics were not measured in all plots.
The RDA of environmental characteristics in monocultures showed that they were clustered in two groups: position on axis 1 was a function of light, soil temperature, $\mathrm{NO}_{3}{ }^{-}$and nitrification, and axis 2 was a function of moisture, $\mathrm{SOM}, \mathrm{NH}_{4}{ }^{+}$and $\mathrm{N}$ mineralization. Therefore, we correlated target performance with the score of each neighbour on each of these axes.

These cross-species correlations were done and should be interpreted as an exploratory analysis; we used Pearson correlations with a two-tailed $t$-test for significance to suggest which patterns are strongest. For a few of the correlations, lichen was excluded from the analysis because lichen is morphologically very different from plants, so some characteristics, such as live biomass (lichen tissue is dense) or light at the soil surface (lichen casts shade at the soil surface but is not very tall) may not be representative of what target plants experienced.

\section{Results}

\section{NET INTERACTIONS}

The five neighbourhoods affected the germination of target species in a consistent hierarchy; Carex and Hieracium facilitated germination for nearly all species, effects of lichen were intermediate, and Danthonia and Schizachyrium mostly negatively affected germination (Table 1a; Fig. 1a; Appendix S2 for means and standard errors). These large, consistent neighbourhood species effects meant that conspecifics vs. heterospecifics did not consistently differ in competitive effect, because a given neighbour species affected all target species similarly (Table 1b; Fig. 1a).

Neighbour identity did not affect the survival of adult transplants, either when classified by neighbour species or by conspecific/heterospecific (Table 1; Fig. 1b; Appendix S2). Overall, the presence of any neighbour facilitated target survival compared to survival in bare plots (most log response ratios were positive).

No consistent hierarchies were found for neighbourhood effect on target adult biomass. Instead, the magnitude of effect depended on a unique combination of the neighbour and target species (significant target $\times$ neighbour interaction) (Table 1a). Specifically, all species performed relatively worse with conspecific rather than with heterospecific neighbours (Table 1b; Fig. 1c; Appendix S2). The magnitude of reduction by conspecifics differed among target species (significant target $\times$ con/het interaction); for example, Danthonia was most negatively affected by conspecifics. Overall, nearly all of the neighbour effects on adult biomass were competitive, not facilitative.

Similarly, no consistent hierarchies were found for neighbourhood effect on target adult total performance, the combined measure of adult survival and growth (Table 1a); rather conspecific neighbours more negatively affected target total performance compared to heterospecific neighbours, and the extent of this reduction tended to vary among target species (nearly significant interaction, Table 1b; Fig. 1d; Appendix S2). In only two instances were heterospecific interactions more negative than conspecific, in the effects of Schizachyrium 
Table 1. Effects of target identity (Carex, Danthonia, Hieracium, Schizachyrium) and either (a) neighbour identity (lichen, Carex, Danthonia, Hieracium, Schizachyrium) or (b) neighbour type (conspecific, heterospecific) on target performance. Target performance for germination, adult biomass, and adult total performance (the combined measure of adult survival and growth) was measured as a log response ratio,

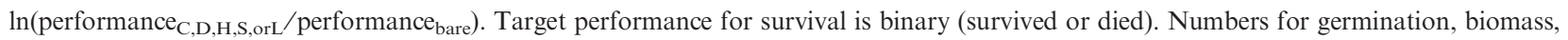
and total performance are $F$ statistics with numerator and denominator degrees of freedom in subscript. Numbers for survival are $\chi^{2}$ values with degrees of freedom in subscript. Block is a random variable and the number shown is a $Z$ statistic testing whether the variance component is different from zero. Significance is indicated by asterisks $\left({ }^{*} P<0.05,{ }^{* *} P<0.01,{ }^{* * *} P<0.001, \dagger P<0.10\right)$

(a)

\begin{tabular}{|c|c|c|c|c|}
\hline Variable & Target species & Neighbour identity & Target $\times$ neighbour & Block \\
\hline Seed germination & $5.19_{3,91.6} * *$ & $8.13_{4,124} * * *$ & $1.50_{12,123}$ & 1.21 \\
\hline Adult survival & $3.94_{2}$ & 1.974 & $5.87_{8}$ & 0.41 \\
\hline Adult biomass & $0.13_{2,41.4}$ & $3.69_{4,42.9^{*}}$ & $3.23_{8,49.3} * *$ & 1.34 \\
\hline Adult total performance & $5.23_{2,81.3} * *$ & $1.04_{4,107}$ & $2.26_{8,98.2} *$ & -0.35 \\
\hline
\end{tabular}

(b)

\begin{tabular}{|c|c|c|c|c|}
\hline Variable & Target species & Conspecific/heterospecific & Target $\times$ con $/$ het & Block \\
\hline Seed germination & $6.32_{3,99.3} * * *$ & $1.17_{1,143}$ & $4.00_{3,99.3^{* *}}$ & 0.97 \\
\hline Adult survival & $8.96_{2}^{*}$ & $0.39_{1}$ & $3.94_{2}$ & 0.29 \\
\hline Adult biomass & $1.94_{2,44.8}$ & $20.74_{1,50.8} * * *$ & $4.37_{2,45.4} *$ & 1.40 \\
\hline Adult total performance & $3.81_{2,31.3} *$ & $7.91_{1,42} * *$ & $2.96_{2,31.3} \dagger$ & -0.93 \\
\hline
\end{tabular}

and lichen on Carex (Fig. 1d). Four heterospecific interactions were facilitative (Fig. 1d).

\section{ASSOCIATIONS BETWEEN NEIGHBOUR SPECIES AND ENVIRONMENTAL CHARACTERISTICS}

Neighbour species identity explained a significant proportion of the total variation in environmental characteristics $(14.8 \%)$ even after the significant effects of shoot biomass and litter mass $(22.5 \%)$ were taken into consideration (Fig. 2). For example, Schizachyrium was associated with high $\mathrm{NH}_{4}{ }^{+}$and SOM, Hieracium had high N mineralization rates, Danthonia had low light levels, and Carex had high light and nitrification rates. Bare and lichen plots also were distinct from plant species neighbourhoods in that bare plots had very high light and nitrification, and lichen had low N mineralization. Similarly, a second RDA on a data set from only August 2007 showed that species identity explained a significant proportion of the environmental variance $(12.3 \%, F=2.41, P=0.002)$ even after accounting for the variation explained by shoot biomass, litter mass, root biomass, and root $\mathrm{C}: \mathrm{N}(31.8 \%, F=6.64$, $P=0.002$; data not shown).

\section{RELATING NET INTERACTIONS TO NEIGHBOUR AND ENVIRONMENTAL CHARACTERISTICS}

To determine if the net effects of neighbour species on target performance (germination and adult total performance) were related to the biomass of the neighbour or its litter, we performed cross-species correlations. For germination, none of the correlations were significant, although all were negative (Appendix S3). For adult total performance, most correlations with biomass were negative, but only significantly so for Danthonia (Fig. 3).

Because many of the abiotic environmental characteristics covaried (Fig. 2), we chose the neighbourhood scores for RDA axis 1 and 2 to represent suites of characteristics to correlate with target performance. Germination was not strongly correlated with either of these suites of characteristics, although all correlations with axis 1 were positive (Appendix S3). Carex and Danthonia adult total performance were positively related to axis 1 (Fig. 4), suggesting increasing performance with increasing light, temperature, $\mathrm{NO}_{3}^{-}$, and nitrification (Fig. 2). Danthonia total performance was negatively related to axis 2 (Fig. 4), suggesting decreasing performance with increasing soil moisture, $\mathrm{SOM}, \mathrm{NH}_{4}{ }^{+}$, and $\mathrm{N}$ mineralization (Fig. 2).

\section{Discussion}

We found that neighbour species created competitive hierarchies in their effects on germination, consistent with our predictions. However, for adult growth, conspecific interactions tended to be more negative than heterospecific interactions creating negative feedbacks among these coexisting species; this is consistent with classic ecological theory, but it is contrary to the majority of pairwise competition experiments (Goldberg \& Barton 1992; Aguiar, Lauenroth \& Peters 2001; Keddy 2001; Cahill et al. 2008). To take a first step in understanding the underlying mechanisms behind these net interactions, we measured abiotic environmental characteristics in field monocultures of each of the dominant species and found that different species are associated with distinct environmental microsites within the grassland. Furthermore, for two of three species, 

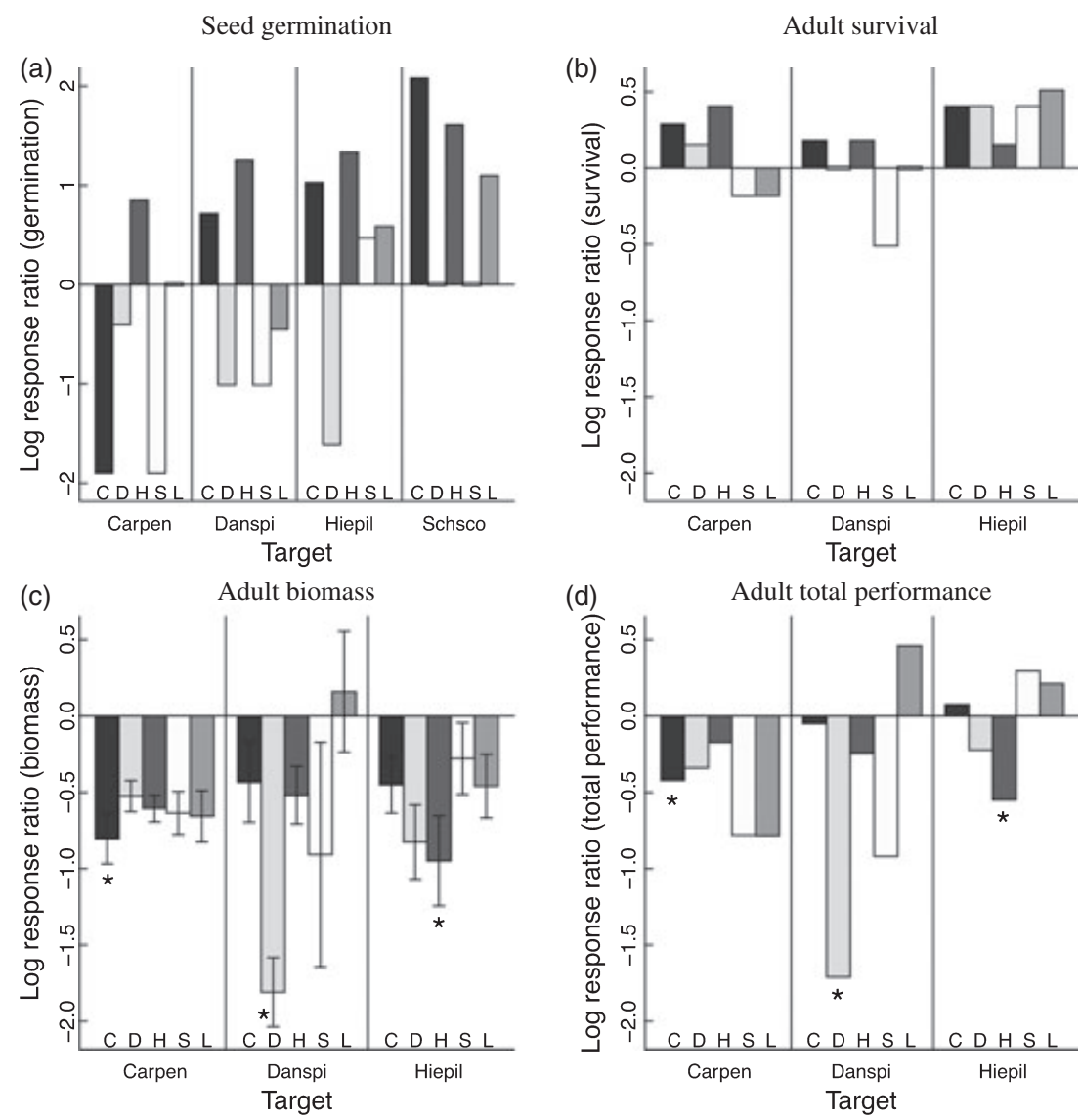

Fig. 1. Relative performance of the target species in different neighbourhoods for (a) seed germination (b) adult survival, (c) adult biomass, and (d) adult total performance (the combined measure of adult survival and growth). Relative performance was calculated by a log response ratio, $\ln$ (performance $\mathrm{C}_{\mathrm{C}, \mathrm{D}, \mathrm{H}, \mathrm{S}, \mathrm{orL}} /$ performance ${ }_{\text {bare }}$ ). The biomass figure has error bars $( \pm 1 \mathrm{SE})$ because log response ratios were calculated by plot and then averaged. Germination, adult survival, and adult total performance figures do not have error bars because log response ratios were calculated on mean performance in neighbourhoods (see Appendix S1). Abbreviations for the target species are: Carpen, Carex pensylvanica; Danspi, Danthonia spicata; and Hiepil, Hieracium piloselloides. Neighbourhood species are represented by different shading and are listed along the bottom of each figure: $\mathrm{C}=$ Carex, $\mathrm{D}=$ Danthonia, $\mathrm{H}=$ Hieracium, $\mathrm{S}=$ Schizachyrium, and $\mathrm{L}=$ lichen. For adult biomass (c) and total performance (d), conspecific bars are marked with an asterisk because there was a significant effect of conspecific vs. heterospecific neighbour on performance (see Table 1).

data suggest that their response to light and nutrient reduction drive the patterns in net adult plant-plant interactions. Below we discuss each of the three components of our study, net interaction, effect on the environment, and response to the environment, and implications for this system and plant interactions more broadly.

\section{NET INTERACTIONS}

Neighbours created a hierarchy in their effects on germination, with Danthonia and Schizachyrium negatively affecting germination of all target species and Carex and Hieracium facilitating germination. Published studies have also shown that diffuse effects of adult vegetation on seedling germination can be either negative or positive (Goldberg 1987b; Reader 1993; Suding \& Goldberg 1999; Howard \& Goldberg 2001; Rebollo et al. 2001). However, only one recent study distinguished the effects of adult neighbour identity on germination and seedling performance in an herbaceous plant community and, similar to our results, found evidence for consistent hierarchies (Fayolle, Violle \& Navas 2009).

The presence of neighbours in general facilitated survival of adult transplants, and this effect was similar across neighbour species. In contrast, the effect of neighbours on target biomass and total performance was highly competitive, and conspecific neighbours tended to affect the target most negatively. The finding that neighbours facilitate survival but inhibit growth is common within and among many plant studies (Goldberg et al. 1999) and is one of the factors that makes it difficult to extrapolate from individual to population consequences of interactions.

Although consistent with classic competition theory, it is nevertheless surprising that, for adult growth, most conspecific interactions are more negative than heterospecific interactions, both in competitive effect and response (i.e. neighbours affect conspecific targets most negatively and targets respond most negatively to conspecific neighbours). In contrast, nearly all glasshouse pot competition experiments find consistent 


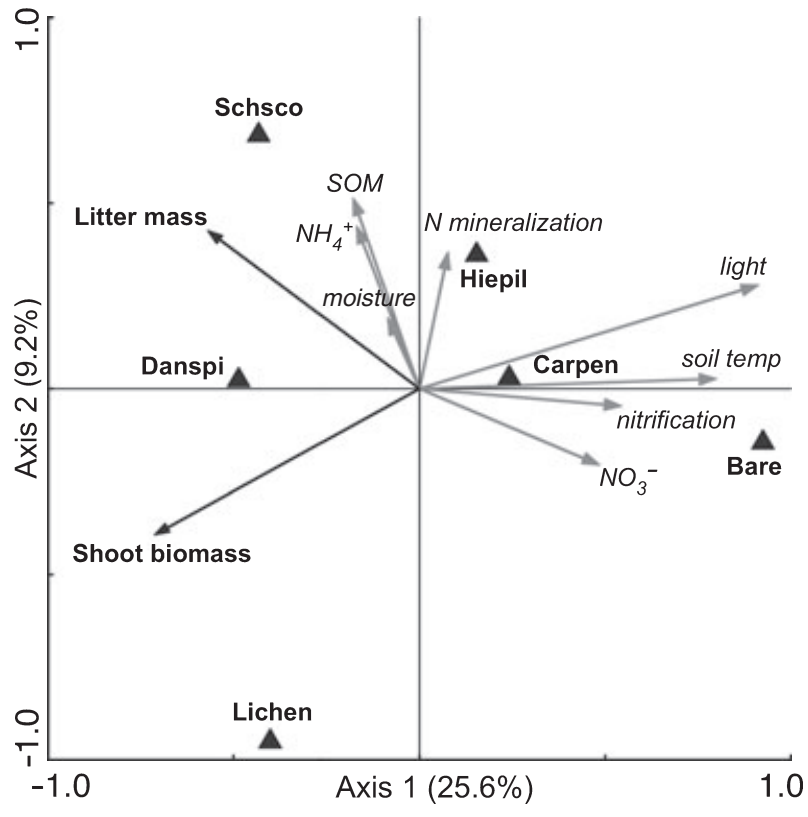

Fig. 2. Biplot from RDA ordination of the relationship among neighbourhood species identity, shoot biomass and litter biomass and environmental variables. Axes 1 and 2 explain $25.6 \%$ and $9.2 \%$ of the total variation, respectively. Block and season were used as covariables in the analysis; block explains $11.0 \%$ and season $14.4 \%$ of the environmental variation. Shoot and litter biomass explain $22.5 \%$ of the environmental variation after accounting for block and season $(F=23.04, P=0.0020)$, and species identity explains an additional $14.8 \%(F=8.09, P=0.0020)$. Abbreviations are as in Fig. 1. Lichen mass was considered 'shoot biomass' in the analysis.

competitive hierarchies (Shipley \& Keddy 1994; Keddy 2001; Cahill et al. 2008). Field competition experiments also tend to find hierarchies in competitive effect and response or else find equivalence of competitors (Goldberg \& Barton 1992; Gurevitch et al. 1992; Goldberg 1996; Aguiar, Lauenroth \& Peters 2001). However, a few field experiments have found intraspecific competition to be stronger than interspecific competition for some species pairs in successional grasslands (Fargione, Brown \& Tilman 2003; Fargione \& Tilman 2005; Dybzinski \& Tilman 2007).

A few differences between our study and classic pairwise competition experiments may explain this inconsistency. First, we chose the neighbour monocultures to be near maximum natural densities. Many of the competition studies that find hierarchies, especially hierarchies in competitive effect, use a single neighbour plant or a constant number of neighbours across all experiments; thus the most competitive species is typically the one with the greatest individual biomass (Goldberg 1987a; Shipley \& Keddy 1994; Rösch, Van Rooyen \& Theron 1997; Keddy 2001). Our study adds realism to these pairwise interactions, by allowing species to compete with neighbours in the field and at their natural densities; for example the species with the smallest individuals, Danthonia, had the largest total neighbour biomass because it occurs in dense clumps. Thus, we are comparing total neighbour effects rather than per capita neighbour effects. Second, our study was carried out over two growing seasons, longer than the typical one-season experiment, which may allow more time for plants to partition resources within a growing season or among years with different precipitation or temperature. In fact, the other competition studies that have found evidence for niche partitioning have been relatively long-term, 3-11 years, and have been carried out in the field (Fargione, Brown \& Tilman 2003; Fargione \& Tilman 2005; Dybzinski \& Tilman 2007). Lastly, the use of mature connected ramets as targets in this experiment, rather than seedlings or isolated ramets, may detect different types of interactions compared to many competition experiments that measure recruitment phase interactions or ignore clonal growth.

\section{ASSOCIATIONS BETWEEN NEIGHBOUR SPECIES AND ENVIRONMENTAL CHARACTERISTICS}

The four plant species were associated with different abiotic environments, which were also distinct from bare or lichen plots. The shoot biomass and litter mass of the neighbour could account for some of this variation in the abiotic environment; for example neighbour types with greater shoot and litter mass had lower levels of light, $\mathrm{NO}_{3}{ }^{-}$, and nitrification, as well as lower temperatures. In contrast, neighbour types with greater litter mass actually had higher levels of other soil resources $\left(\mathrm{NH}_{4}{ }^{+}\right.$, moisture) or indicators (SOM). Negative live biomass effects on resources such as $\mathrm{NO}_{3}{ }^{-}$and light are likely due to direct uptake, because large plants have greater nutrient demand and ability to shade. However, counterintuitively, the two plant species with the greatest biomass, Danthonia and Schizachyrium, had the highest $\mathrm{NH}_{4}{ }^{+}$levels. This result appeared to be related to their high litter amounts. Litter is the source of organic matter in the soil and can affect $\mathrm{N}$ pools directly through release during decomposition (Eviner \& Chapin 2003). The shading effect of litter also reduces temperature and retains soil moisture.

However, even after accounting for neighbour shoot and litter biomass, a significant amount of the remaining variance in environmental characteristics could be accounted for by neighbour species per se. This indicates that other characteristics such as the microbial community associated with each species or differences in per gram uptake rates, plant tissue quality (C:N, lignin, etc.) or leaf architecture are important in driving abiotic environmental differences in different neighbourhoods (Hobbie 1992; Eviner \& Chapin 2003). For example, lichen patches had very low $\mathrm{SOM}, \mathrm{NH}_{4}{ }^{+}$and $\mathrm{N}$ mineralization rates, which has been found in other studies and is likely due to their slow growth rate, lack of below-ground structures and complex secondary chemistry (Sedia \& Ehrenfeld 2005). Danthonia, Schizachyrium, and lichen all exhibited low nitrification rates, which may also be due to litter chemistry (Wedin \& Tilman 1990; Eviner \& Chapin 2003).

\section{RELATING NET INTERACTIONS TO NEIGHBOUR AND ENVIRONMENTAL CHARACTERISTICS}

To take a first step to identify intermediaries that may play a role in net interactions, we explored relationships between 

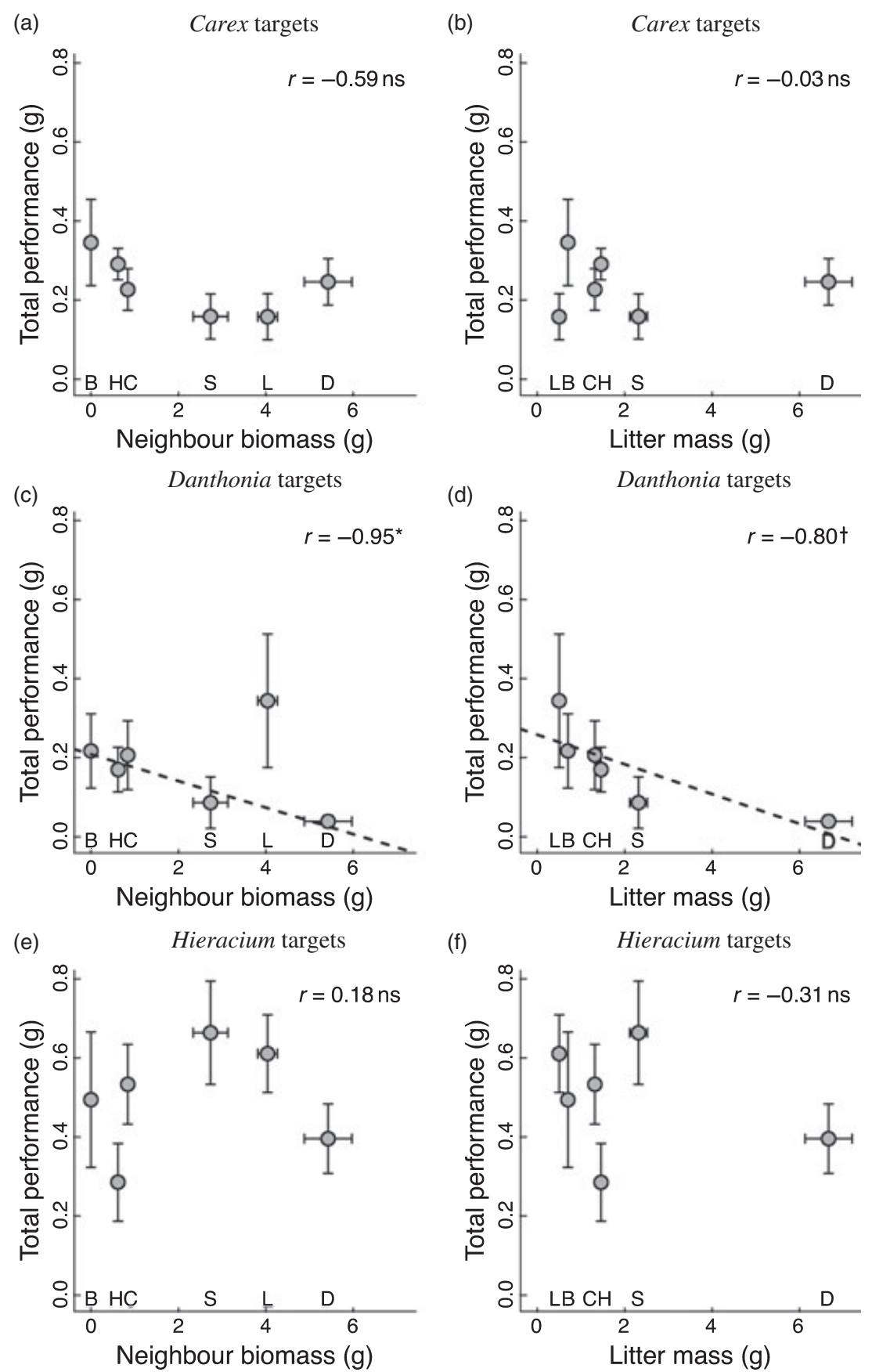

Fig. 3. Relationship between neighbour biomass and litter mass and adult total performance of Carex (a and b), Danthonia (c and d) and Hieracium (e and f). Each point represents mean target performance and mean neighbour mass $( \pm 1 \mathrm{SE})$ in one neighbour type; neighbour types are listed along the $x$-axis (abbreviations as in Fig. 1). Pearson correlation coefficients are shown in the upper right corner and dashed lines indicate a significant or nearly significant correlation $\left({ }^{*} P<0.05, * * P<0.01, \uparrow P<0.10, \mathrm{NS}=\right.$ not significant); for (c), the correlation excludes the outlier, lichen (correlation including lichen is $-0.26 \mathrm{~ns}$ ). target performance and characteristics of the neighbours and their environments.

For germination, the hierarchy in competitive effect was related to neighbour biomass; specifically, neighbours with large biomass (Danthonia and Schizachyrium) had competitive effects on germination, while neighbours with lower biomass (Carex and Hieracium) facilitated germination. This is consistent with the positive, although non-significant, correlations between germination rates and RDA axis 1 , which was correlated with light. It may also be indicative of nonlinear responses of germination to neighbour biomass and environmental variables such as light and temperature. For example, a small amount of above-ground biomass may facilitate germination due to temperature amelioration but a large amount may inhibit it due to decreased light; however a larger comparative study would be necessary to test this.

For adult total performance for the target Danthonia, both neighbour biomass and litter mass negatively affected performance, while increasing light, temperature, $\mathrm{NO}_{3}{ }^{-}$, and nitrification (RDA axis 1) positively affected performance. Light reduction by both living and dead plant material is the most likely intermediary driving the pattern of conspecific vs. heterospecific effects for Danthonia, because Danthonia neighbours had the largest biomass and litter mass and lowest light levels in the field (Danthonia neighbourhoods did not have the lowest $\mathrm{NO}_{3}{ }^{-}$or nitrification so those factors are not 
Fig. 4. Relationship between environmental characteristics (RDA axes 1 and 2, Fig. 2) and adult total performance for Carex (a and b), Danthonia (c and d), and Hieracium (e and f). RDA axis 1 is positively correlated with light, soil temperature, $\mathrm{NO}_{3}{ }^{-}$, and nitrification; $\mathrm{RDA}$ axis 2 is positively correlated with moisture, SOM, $\mathrm{NH}_{4}{ }^{+}$, and $\mathrm{N}$ mineralization. Each point represents mean performance $( \pm 1 \mathrm{SE})$ and RDA score in one neighbour type; neighbour types are listed along the $x$-axis (abbreviations as in Fig. 1). Pearson correlation coefficients are shown in the upper right corner and dashed lines indicate a significant or nearly significant correlation $\left({ }^{*} P<0.05\right.$, $* * P<0.01, \dagger P<0.10$, NS $=$ not significant); for (c), the correlation excludes the outlier, lichen (correlation including lichen is $0.28 \mathrm{~ns})$.
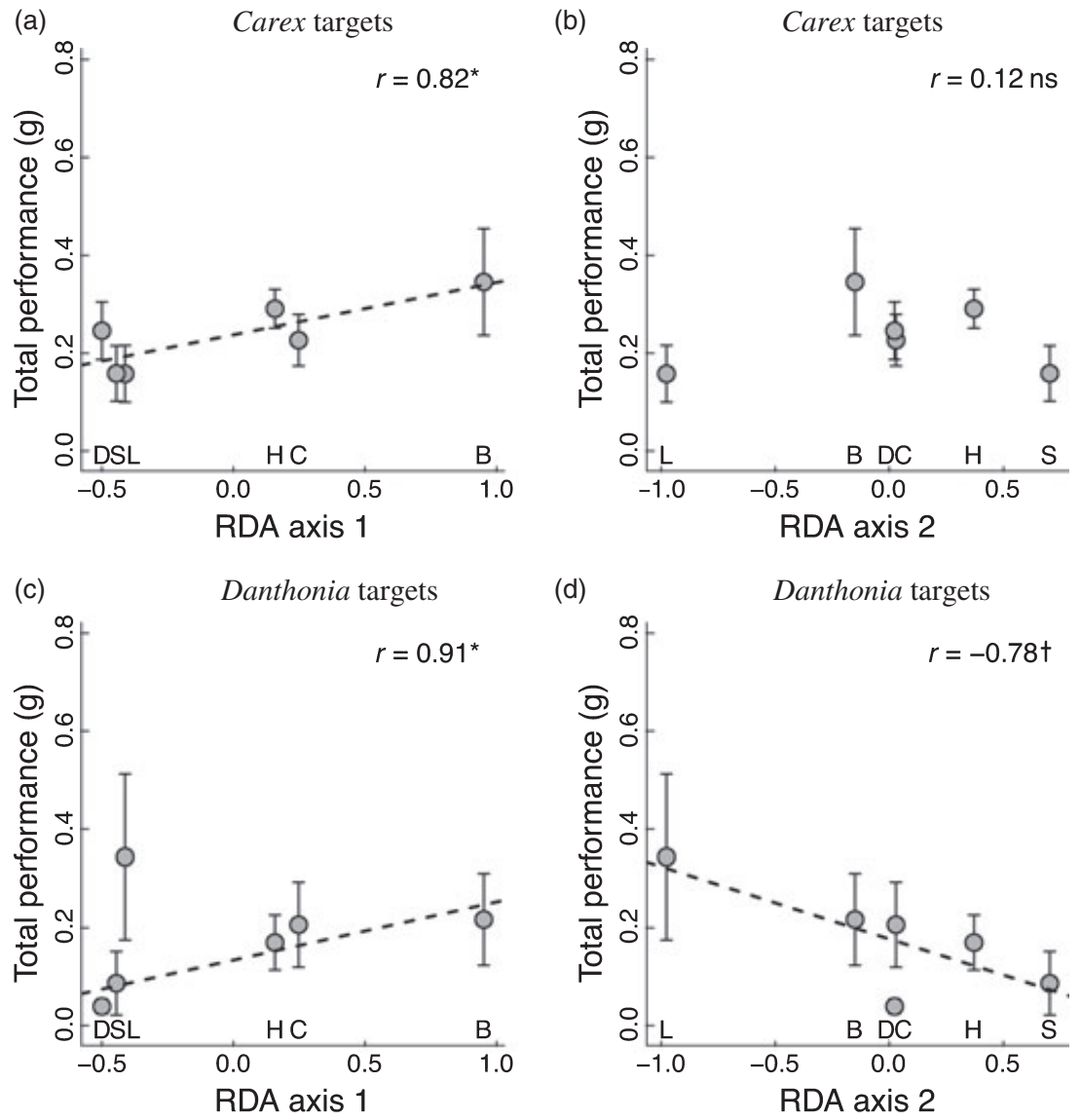

(d)
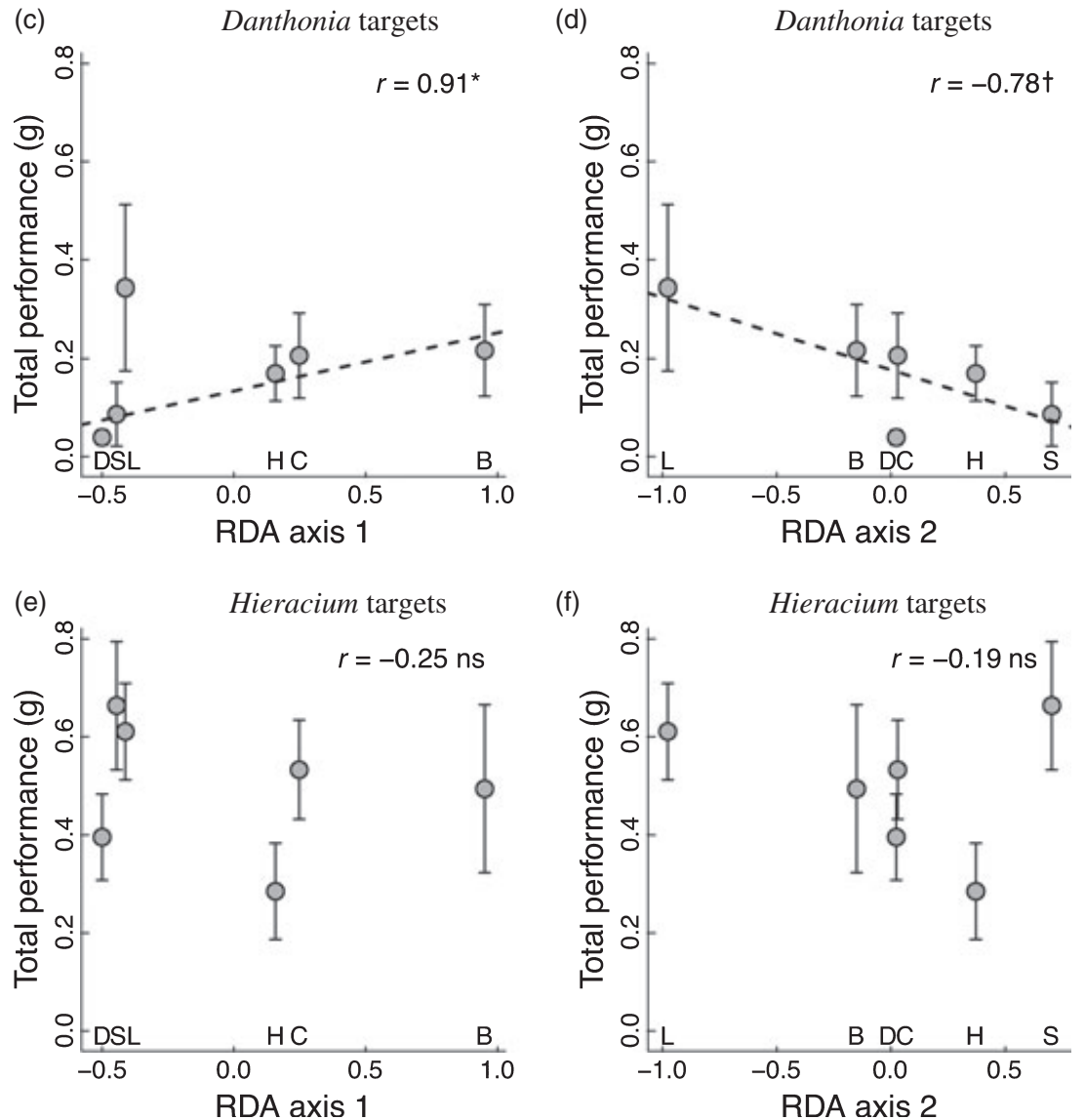

responsible for the conspecific/heterospecific pattern). Adult Carex performance showed a threshold effect, that targets were largest in plots with no neighbours but that the presence of any neighbour reduced growth to the same extent. This could be explained by the fact that all neighbours reduced light and $\mathrm{NO}_{3}{ }^{-}$relative to no neighbour plots and is consistent with the positive correlation between Carex performance and RDA axis 1 (light, temperature, $\mathrm{NO}_{3}{ }^{-}$, and nitrification). However, for Hieracium adult total performance, neither neighbour mass nor environmental characteristics could explain the pattern of conspecific competition being greater than heterospecific competition. Root ingrowth of non-neighbour species into the field monoculture patches may reduce our ability to detect neighbour effects on resources or correlations between resources and target performance; however, if we do not detect it in our field setting in which we chose monoculture patches, we are confident that it is not important to field population dynamics in general.

The ability of resource depletion or neighbour effects on abiotic intermediaries to explain differences in neighbour competitive effects only for some species (Carex and Danthonia) but not for others (Hieracium) is consistent with the few other competition studies that have measured the abiotic environment (Reynolds et al. 1997; Fargione, Brown \& Tilman 2003; Dybzinski \& Tilman 2007). For Hieracium, the fact that Hieracium neighbours had the strongest negative impact on Hieracium targets, despite not having the largest impact on any of the abiotic intermediaries could simply indicate that we did not 
measure the relevant abiotic variable, that spatial or temporal differences in an abiotic variable are more important than static values or that net interactions may be mediated by soil biota or herbivores rather than resources or abiotic conditions.

Spatial partitioning of rooting depth has been found to promote coexistence in other grasslands (Fargione \& Tilman 2005), and may have contributed to our patterns of conspecific and heterospecific interactions. We only took measurements from the top $10 \mathrm{~cm}$ of soil and, although the majority of roots were within this depth, some roots, notably Schizachyrium, went considerably deeper and are likely accessing water at depth. Temporal resource partitioning within a season or among years is also possible, and has been found to be important in other studies (McKane, Grigal \& Russelle 1990; Fargione \& Tilman 2005). Carex, Danthonia, and Hieracium all flower in the spring, whereas Schizachyrium flowers in the fall, and resource demands may consequently differ seasonally. Also, Danthonia and Hieracium tend to take advantage of cool, wet springs (Farrer, Goldberg \& King 2010), and thus species may partition years in this manner. Any of these mechanisms could explain the lack of strong competitive effects of Schizachyrium on the other species. Unfortunately, too few Schizachyrium transplants survived to assess whether it is also a weak conspecific competitor.

Species also may accumulate detrimental microbial communities in the local soil environment, so that transplants perform worse in conspecific neighbourhoods. Glasshouse feedback experiments typically find that negative feedbacks dominate due to certain mycorrhizas (Bever 2002; Klironomos 2002; Casper \& Castelli 2007) or fungal pathogens (Bever 1994; Holah \& Alexander 1999; Klironomos 2002; Kardol et al. 2007). However, when feedback experiments are performed in the field (Bezemer et al. 2006; Kulmatiski et al. 2008) or incorporate live competition (Casper \& Castelli 2007) negative feedbacks are much less consistently found. Similarly, other studies have found that soil source influences competitive ability for some species (Reynolds et al. 1997; Van der Putten \& Peters 1997; Reinhart \& Callaway 2006; Petermann et al. 2008) but not others (Bever 1994; Reinhart \& Callaway 2006). These results suggest that the balance of different intermediaries is idiosyncratic; sometimes resource mechanisms dominate the net interaction, while sometimes microbial intermediaries dominate. Further complicating our ability to predict the outcome of net interactions are positive effects of neighbours on some resources or conditions, especially in unproductive environments (Eviner \& Chapin 2003; Brooker et al. 2008). While there is now a very large literature documenting facilitative interactions between plants, especially in unproductive environments, relatively few studies focused on facilitation have examined conspecific vs. heterospecific interactions. In order to test the combined net effect of all abiotic and biotic intermediaries which may interact (De Deyn, Raaijmakers \& Van der Putten 2004) to determine population dynamics, studies need to be performed in the field and with neighbour plants; manipulations of the different intermediaries could sort out their relative magnitudes.

\section{Conclusions}

We found that species create hierarchies in competitive effect for germination but not for adult performance. Competitive hierarchies may be more common at early stages of a plants, life history in which competition is very asymmetric and species have similar requirements and susceptibility (i.e. all seedlings are small relative to their neighbours, seedlings all need light and are susceptible to desiccation). For adult growth, where competition is more symmetric and species may be more differentiated in terms of phenology and morphology, niche processes may be more likely to be important. These niches may be driven by resource reduction, as in the case of Danthonia neighbours reducing light levels, modification of soil microbial communities, or other types of partitioning such as rooting depth.

Coexistence theory is based on population-level interactions, not individual interactions. In this study, we take a first step towards adopting this approach and incorporate neighbour effects on multiple components of fitness, including germination and adult survival and growth, to try to scale up to the population-level. Our data suggest that sexual reproduction may not be very important to population growth in this system due to very low germination and establishment rates; this is not surprising based on the hot, stressful conditions in the dry sand prairie. Therefore population growth is likely largely driven by clonal expansion, which we captured in our adult transplant experiment by transplanting clones, and which suggests stabilizing niche processes exist for two of the three species.

This interpretation is strengthened by previous work in this system in which we fit population dynamic models to longterm survey data to estimate population demographic and interaction coefficients (Farrer, Goldberg \& King 2010). We found similar results in that seed colonization rates were very low and that per capita adult interaction coefficients were generally more negative for conspecific than heterospecific interactions. Thus, despite the different methods and metrics used for measuring interactions, this concordance suggests that some stabilizing processes are occurring in this system. Moreover, the experiment presented here identifies resource intermediaries that likely regulate some of these community dynamics but also suggests that microbial intermediaries or other forms of resource partitioning could also play a role.

\section{Acknowledgements}

We thank N. Cabrera-Schneider, J. Farrer, A. Greiner-Urbanik, G. Milanowski, C. Leonetti, L. Sullivan, and R. Wildova for their assistance in the field and laboratory. J. Le Moine and M. Grant helped with soil chemistry. We thank the Indian River DNR for their cooperation in doing research on state-owned land. Two referees gave thoughtful comments on an earlier draft of this manuscript. This research was supported by fellowships from the University of Michigan Biological Station, the Nature Conservancy, the University of Michigan, Department of Ecology and Evolutionary Biology, and the Helen Olson Brower Memorial Fellowship.

\section{References}

Aguiar, M.R., Lauenroth, W.K. \& Peters, D.P. (2001) Intensity of intra- and interspecific competition in coexisting shortgrass species. Journal of Ecology, 89, $40-47$. 
Albert, D.A. (1995) Regional Landscape Ecosystems of Michigan, Minnesota, and Wisconsin: A working Map and Classification. Gen. Tech. Rep. NC-178. U.S. Department of Agriculture, Forest Service, North Central Forest Experiment Station. Northern Prairie Wildlife Research Center Home Page. Available at: http://www.npwrc.usgs.gov/resource/habitat/rlandscp/index. htm (Version 03JUN98), St. Paul, MN.

Bever, J.D. (1994) Feedback between plants and their soil communities in an old field community. Ecology, 75, 1965-1977.

Bever, J.D. (2002) Negative feedback within a mutualism: host-specific growth of mycorrhizal fungi reduces plant benefit. Proceedings of the Royal Society of London Series B-Biological Sciences, 269, 2595-2601.

Bever, J.D. (2003) Soil community feedback and the coexistence of competitors: conceptual frameworks and empirical tests. New Phytologist, 157, 465473.

Bezemer, T.M., Lawson, C.S., Hedlund, K., Edwards, A.R., Brook, A.J., Igual, J.M., Mortimer, S.R. \& Van der Putten, W.H. (2006) Plant species and functional group effects on abiotic and microbial soil properties and plant-soil feedback responses in two grasslands. Journal of Ecology, 94, 893904.

ter Braak, C.J.F. (1987) CANOCO - A FORTRAN Program for Canonical Community Ordination by (Partial) (Detrended) (Canonical) Correspondence Analysis, Principal Components Analysis, and Redundancy Analysis (Version 2.1). TNO Institute for Applied Computer Science, Statistics Department, Wageningen.

ter Braak, C.J.F. \& Smilauer, P. (1998) Canoco Reference Manual and User's Guide to Canoco for Windows: Software for Canonical Community Ordination. Version 4. Microcomputer Power, Ithaca, NY, USA.

Brooker, R.W., Maestre, F.T., Callaway, R.M., Lortie, C.L., Cavieres, L.A., Kunstler, G. et al. (2008) Facilitation in plant communities: the past, the present, and the future. Journal of Ecology, 96, 18-34.

Cahill, J.F., Kembel, S.W., Lamb, E.G. \& Keddy, P.A. (2008) Does phylogenetic relatedness influence the strength of competition among vascular plants? Perspectives in Plant Ecology Evolution and Systematics, 10, 41-50.

Callaway, R.M. \& Walker, L.R. (1997) Competition and facilitation: a synthetic approach to interactions in plant communities. Ecology, 78, 19581965.

Casper, B.B. \& Castelli, J.P. (2007) Evaluating plant-soil feedback together with competition in a serpentine grassland. Ecology Letters, 10, 394-400.

Chase, J.M. \& Leibold, M.A. (2003) Ecological Niches: Linking Classical and Contemporary Approaches. University of Chicago Press, Chicago, IL, USA.

Chesson, P. (2000) Mechanisms of maintenance of species diversity. Annual Review of Ecology and Systematics, 31, 343-366.

De Deyn, G.B., Raaijmakers, C.E. \& Van der Putten, W.H. (2004) Plant community development is affected by nutrients and soil biota. Journal of Ecology, 92, 824-834

Dybzinski, R. \& Tilman, D. (2007) Resource use patterns predict long-term outcomes of plant competition for nutrients and light. American Naturalist, 170, 305-318.

Eviner, V.T. \& Chapin, F.S. III (2003) Functional matrix: a conceptual framework for predicting multiple plant effects on ecosystem processes. Аппиаl Review of Ecology and Systematics, 34, 455-485.

Fargione, J., Brown, C.S. \& Tilman, D. (2003) Community assembly and invasion: an experimental test of neutral versus niche processes. Proceedings of the National Academy of Sciences of the United States of America, 100, 8916 8920.

Fargione, J. \& Tilman, D. (2005) Niche differences in phenology and rooting depth promote coexistence with a dominant C4 bunchgrass. Oecologia, 143, 598-606.

Farrer, E.C., Goldberg, D.E. \& King, A.A. (2010) Time lags and the balance of positive and negative interactions in driving grassland community dynamics. American Naturalist, 175, 160-173.

Fayolle, A., Violle, C. \& Navas, M.L. (2009) Differential impacts of plant interactions on herbaceous species recruitment: disentangling factors controlling emergence, survival and growth of seedlings. Oecologia, 159, $817-825$.

Fischer, M. \& van Kleunen, M. (2002) On the evolution of clonal plant life histories. Evolutionary Ecology, 15, 565-582.

Goldberg, D.E. (1987a) Neighborhood competition in an old-field plant community. Ecology, 68, 1211-1223.

Goldberg, D.E. (1987b) Seedling colonization of experimental gaps in 2 oldfield communities. Bulletin of the Torrey Botanical Club, 114, 139-148.

Goldberg, D.E. (1996) Competitive ability: definitions, contingency and correlated traits. Philosophical Transactions of the Royal Society of London Series B-Biological Sciences, 351, 1377-1385.
Goldberg, D.E. \& Barton, A.M. (1992) Patterns and consequences of interspecific competition in natural communities: a review of field experiments with plants. The American Naturalist, 139, 771-801.

Goldberg, D.E., Turkington, R. \& Olsvig-Whittaker, L. (1995) Quantifying the community-level consequences of competition. Folia Geobotanica \& Phytotaxonomica, 30, 231-242.

Goldberg, D.E., Rajaniemi, T., Gurevitch, J. \& Stewart-Oaten, A. (1999) Empirical approaches to quantifying interaction intensity: competition and facilitation along productivity gradients. Ecology, 80, 1118-1131.

Gurevitch, J., Morrow, L.L., Wallace, A. \& Walsh, J.S. (1992) A metaanalysis of competition in field experiments. The American Naturalist, 140, 539-572

Hobbie, S.E. (1992) Effects of plant species on nutrient cycling. Trends in Ecology and Evolution, 7, 336-339.

Holah, J.C. \& Alexander, H.M. (1999) Soil pathogenic fungi have the potential to affect the coexistence of two tallgrass prairie species. Journal of Ecology, 87, 589-608.

Howard, T.G. \& Goldberg, D.E. (2001) Competitive response hierarchies for germination, growth, and survival and their influence on abundance. Ecology, 82, 979-990.

Kardol, P., Cornips, N.J., van Kempen, M.M.L., Bakx-Schotman, J.M.T. \& Van der Putten, W.H. (2007) Microbe-mediated plant-soil feedback causes historical contingency effects in plant community assembly. Ecological Monographs, 77, 147-162.

Kashian, D.M., Barnes, B.V. \& Walker, W.S. (2003) Ecological species groups of landform-level ecosystems dominated by jack pine in northern Lower Michigan, USA. Plant Ecology, 166, 75-91.

Keddy, P.A. (2001) Competition. Kluwer Academic Publishers, Dordrecht.

Klironomos, J.N. (2002) Feedback with soil biota contributes to plant rarity and invasiveness in communities. Nature, 417, 67-70.

Kost, M.A., Albert, D.A., Cohen, J.G., Slaughter, B.S., Schillo, R.K., Weber, C.R. \& Chapman, K.A. (2007) Natural Communities of Michigan: Classification and Description. Michigan Natural Features Inventory, Report Number 2007-21, Lansing, MI, USA.

Kulmatiski, A., Beard, K.H., Stevens, J.R. \& Cobbold, S.M. (2008) Plant-soil feedbacks: a meta-analytical review. Ecology Letters, 11, 980-992.

McKane, R.B., Grigal, D.F. \& Russelle, M.P. (1990) Spatiotemporal difference in ${ }^{15} \mathrm{~N}$ uptake and the organization of an old-field plant community. Ecology, 71, 1126-1132.

Petermann, J.S., Fergus, A.J.F., Turnbull, L.A. \& Schmid, B. (2008) JanzenConnell effects are widespread and strong enough to maintain diversity in grasslands. Ecology, 89, 2399-2406.

Reader, R.J. (1993) Control of seedling emergence by ground cover and seed predation in relation to seed size for some old-field species. Journal of Ecology, 81, 169-175.

Rebollo, S., Perez-Camacho, L., Garcia-de Juan, M.T., Benayas, J.M.R. \& Gomez-Sal, A. (2001) Recruitment in a Mediterranean annual plant community: seed bank, emergence, litter, and intra- and inter-specific interactions. Oikos, 95, 485-495.

Reinhart, K.O. \& Callaway, R.M. (2006) Soil biota and invasive plants. New Phytologist, 170, 445-457.

Reynolds, H.L., Hungate, B.A., Chapin, F.S. III \& D'Antonio, C.M. (1997) Soil heterogeneity and plant competition in an annual grassland. Ecology, 78, 2076-2090.

Rösch, H., Van Rooyen, M.W. \& Theron, G.K. (1997) Predicting competitive interactions between pioneer plant species by using plant traits. Journal of Vegetation Science, 8, 489-494.

Sedia, E.G. \& Ehrenfeld, J.G. (2005) Differential effects of lichens, mosses and grasses on respiration and nitrogen mineralization in soils of the New Jersey Pinelands. Oecologia, 144, 137-147.

Shipley, B. \& Keddy, P.A. (1994) Evaluating the evidence for competitive hierarchies in plant communities. Oikos, 69, 340-345.

Silvertown, J. (2004) Plant coexistence and the niche. Trends in Ecology \& Evolution, 19, 605-611.

Suding, K.N. \& Goldberg, D.E. (1999) Variation in the effects of vegetation and litter on recruitment across productivity gradients. Journal of Ecology, 87, 436-449.

Tilman, D. (1990) Constraints and tradeoffs: toward a predictive theory of competition and succession. Oikos, 58, 3-15.

Van der Putten, W.H. \& Peters, B.A.M. (1997) How soil-borne pathogens may affect plant communities. Ecology, 78, 1785-1795.

Voss, E.G. (1972) Michigan Flora, Part I: Gymnosperms and Monocots. Cranbrook Institute of Science, Bloomfield Hills, MI, USA.

Voss, E.G. (1996) Michigan Flora, Part III: Dicots Continued (PyrolaceaeCompositae). Cranbrook Institute of Science, Bloomfield Hills, MI, USA. 
Wedin, D.A. \& Tilman, D. (1990) Species effects on nitrogen cycling: a test with perennial grasses. Oecologia, 84, 433-441.

Received 8 April 2010; accepted 16 August 2010

Handling Editor: James Cahill

\section{Supporting Information}

Additional Supporting Information may be found in the online version of this article:

Appendix S1. Supplementary methodology.

Appendix S2. Means and standard errors for germination and establishment from the seed addition experiment and adult survival, biomass, and total performance from the transplant experiment in the six neighbourhood types.

Appendix S3. Cross-species correlations between germination and neighbour/environmental characteristics.

As a service to our authors and readers, this journal provides supporting information supplied by the authors. Such materials may be reorganized for online delivery, but are not copy-edited or typeset. Technical support issues arising from supporting information (other than missing files) should be addressed to the authors. 